\title{
Enhancing Business Intelligence Quality with Visualization: An Experiment on Stakeholder Network Analysis
}

\author{
Wingyan Chung \\ Department of Operations and Management Information Systems, \\ Leavey School of Business, Santa Clara University, \\ Santa Clara, CA 95053, USA. \\ wchung@scu.edu
}

\begin{abstract}
Business intelligence $(\mathrm{BI})$ has gained a strategic importance in today's global competitive environment. However, high-quality $\mathrm{Bl}$ is not easy to obtain on the Web due to information overload and difficulty to present complicated relationships among various types of business stakeholders. Unfortunately, existing $\mathrm{Bl}$ tools lack the capability of analyzing and visualizing such relationships and research on $B I$ systems is sparse. In this paper, we review the current market of $\mathrm{BI}$ tools and related research, describe an approach to support the development of tools that provide high-quality $\mathrm{Bl}$, and report the findings of a user evaluation study of the prototype developed based on the proposed approach. The approach combines information visualization and Web mining techniques with human knowledge to enable business analysts to analyze and visualize complicated business stakeholder relationships. Results of an experiment involving 62 subjects show that the prototype significantly outperformed a traditional method of $\mathrm{BI}$ analysis in terms of efficiency, quality of BI, and user satisfaction. The subjects provided favorable comments and expressed strong preferences toward the prototype in most applications. This research contributes to advancing $B I$ research and to providing new empirical findings for Bl systems evaluation.
\end{abstract}

Keywords: Business intelligence, BI tools, stakeholder theory, stakeholder network analysis, Web searching and browsing, information visualization, experiment. 


\section{Introduction}

Business intelligence has become an important issue of organizational management in today's global competitive environment (Blenkhorn and Fleisher, 2005, Chung et al., 2005b, Miller, 2000). Managers rely on business intelligence $(\mathrm{BI})$ to monitor the operating environment, to identify potential risks, and to devise competitive strategies (Fleisher and Blenkhorn, 2003, Gilad, 2004). Rooted in the military domain, $\mathrm{BI}$ is the product of acquisition, collation, analysis, interpretation, and exploitation of business information (Chung et al., 2005b, Davies, 2002). In the business world, BI can be obtained from analyzing a company's (internal) operational data (such as the financial statements (Rasmussen et al., 2002), sales and transaction records (Hurd and Nyberg, 2004)) and from studying the company's (external) competitive environment and stakeholders (e.g., supply market [Handfield, 2006] and various stakeholders' concerns (Freeman, 1984)). Standard IT solutions exist for analyzing a company's internal data, including statistical software, online analytical processing, data warehousing, and data mining (Turban et al., 2005, Whitehorn and Whitehorn, 1999). In contrast, methods and technologies for studying a company's external environment and stakeholders are less standardized due to the relatively unstructured nature of the data.

Traditionally, significant manual efforts are needed to obtain $\mathrm{BI}$ from business stakeholders, such as interview, searching for published and unpublished documents, monitoring news sources, and observing competitors' movements (Kassler and Sandman, 2000). As more and more businesses use the Web to share information with stakeholders, the problems arising from information overload and interconnected nature of the Web make it difficult to obtain BI. Information overload occurs when not all Web pages about stakeholders can be processed and utilized by a human user, leading to an inadequate understanding of the competitive environment (Bowman et al., 1994). The hyperlinked Web environment supports extensive inter-connection among Web pages, enhancing communication in stakeholder networks while creating disorientation among Web users (Nielsen, 1990) and aggravating the information overload problem. For instance, a business analyst may obtain from a simple Web search thousands of Web pages about his company's stakeholders and is not able to analyze them. Consequently, important yet complex stakeholder relationships are buried in voluminous interconnected Web pages. Information about these stakeholders and relationships, if properly identified and portrayed, would become valuable business intelligence to help managers understand the competitive environment, locate new business opportunities, and improve relationships with customers, suppliers, government agencies, and other stakeholders.

To address the aforementioned needs, this research proposes an approach to discovering high-quality $\mathrm{BI}$ from stakeholders connected to companies via the World Wide Web. The approach combines information visualization and Web mining techniques with human knowledge to enable business analysts to analyze and visualize complicated business stakeholder relationships. We conducted an experiment involving 62 subjects to compare empirically the quality of BI obtained by two methods: the prototype developed based on the approach and a traditional method of $\mathrm{BI}$ analysis via manual browsing and searching of stakeholder information on the Web. We analyzed the subjects' verbal comments and evaluated the quality of $\mathrm{BI}$ obtained by the two methods. Our goals in this research were to contribute to advancing the research and practice of $\mathrm{BI}$ and to providing new empirical findings of evaluating $\mathrm{BI}$ systems.

\section{Literature Review}

An organization's survival and continuing prosperity depends on its ability to create sufficient wealth, value, or satisfaction for all 
primary stakeholder groups (Clarkson, 1995). The idea that organizations have stakeholders is well conceived in the management literature (Freeman, 1984, Mitchell et al., 1997) and the study of firms that has evolved over the past centuries (Barnard, 1938, Berle and Means, 1932, Smith, 1759). The term "stakeholder" refers to any individuals or organizations that affect or are affected by the accomplishment of the firm's objectives (Freeman, 1984). Examples of stakeholders include customers, suppliers, government agencies, the general public, financial institutions, and trade associations. Table 1 summarizes stakeholder types considered in recent research.

\begin{tabular}{|c|c|c|c|c|c|c|c|c|c|c|c|c|c|c|c|}
\hline Research & $\mathbf{P}$ & $\mathbf{E}$ & C & $\mathbf{S}$ & $\mathbf{U}$ & $\mathbf{M}$ & $\mathbf{G}$ & $\mathbf{R}$ & V & 0 & $\mathbf{T}$ & $\mathbf{F}$ & I & $\mathbf{N}$ & No. \\
\hline Reid, 2003 & $\checkmark$ & $\checkmark$ & $\checkmark$ & $\checkmark$ & $\checkmark$ & $\checkmark$ & $\checkmark$ & $\checkmark$ & $\checkmark$ & $\checkmark$ & & & & & 10 \\
\hline Jawahar \& McLaughlin, 2001 & $\checkmark$ & $\checkmark$ & $\checkmark$ & $\checkmark$ & & & $\checkmark$ & & & $\checkmark$ & $\checkmark$ & $\checkmark$ & & $\checkmark$ & 9 \\
\hline Elias \& Cavana, 2000 & $\checkmark$ & $\checkmark$ & $\checkmark$ & $\checkmark$ & & $\checkmark$ & $\checkmark$ & & & $\checkmark$ & & $\checkmark$ & & $\checkmark$ & 9 \\
\hline Agle et al., 1999 & & $\checkmark$ & $\checkmark$ & $\checkmark$ & & & $\checkmark$ & & & & & & & $\checkmark$ & 5 \\
\hline Donaldson \& Preston, 1995 & $\checkmark$ & $\checkmark$ & $\checkmark$ & $\checkmark$ & & & $\checkmark$ & & & & $\checkmark$ & & $\checkmark$ & $\checkmark$ & 8 \\
\hline Clarkson, 1995 & $\checkmark$ & $\checkmark$ & $\checkmark$ & $\checkmark$ & & & $\checkmark$ & & & & & & & & 5 \\
\hline No. & 5 & 6 & 6 & 6 & 1 & 2 & 6 & 1 & 1 & 3 & 2 & 2 & 1 & 4 & - \\
\hline
\end{tabular}

Advances in information technology have enabled management to serve and to understand its stakeholders better, primarily through more effective and efficient collection, storage, and analysis of information from the business environment. In recent years, a new class of information technology known as business intelligence (BI) systems emerged to support such tasks (Negash, 2004). In this section, we review existing tools and technology of business analytics and $\mathrm{BI}$ systems. In addition, we review technologies in Web mining and information visualization, two emerging technologies having potential to support $\mathrm{BI}$ tasks and to alleviate information overload problems.

\section{Business Intelligence Systems}

Business intelligence systems enable organizations to understand their internal and external environments through systematic acquisition, collation, analysis, interpretation and exploitation of information (Cronin, 2000, Nolan, 1999). Two classes of BI tools have been defined (Carvalho and Ferreira, 2001). The first class of these is used to manipulate massive operational data and to extract essential business information from them. Examples include decision support systems, executive information systems, onlineanalytical processing (OLAP), data warehouses, and data mining systems that are built upon database management systems to reveal hidden trends and patterns (Choo, 1998). The second class of BI tools, also called competitive intelligence tools, aims at systematically collecting and analyzing information from the business environment and stakeholders to assist in organizational decision making. They mainly gather information from public sources such as the Web.

\section{BI Quality}

Although these $\mathrm{BI}$ tools provide insights into various value-adding processes in knowledge discovery, studies of the quality of $\mathrm{BI}$ obtained by using $\mathrm{BI}$ tools are rarely found. In 
contrast, information quality has been studied in other areas, such as English Web searching (Loiacono, 2002, Marsico and Levialdi, 2004), non-English search engines (Chung, 2006), organizations (Wang and Strong, 1996), and companies (Pipino et al., 2002). Empirical studies into the quality of $\mathrm{BI}$, if available, would enhance the understanding of the performance of $\mathrm{BI}$ tools and provide insights for BI system evaluation.

\section{Functionality of BI Systems}

Having studied the market of $\mathrm{Bl}$ tools and software, Fuld and Singh (Fuld and Singh, 2005) found in recent years significant technological improvements among BI tools. Most of the 219 respondents in Fuld's survey considered a key strength of $\mathrm{BI}$ tools to be their ability to collect information, although $30 \%$ of all respondents criticized these tools for their lack of added-value and for consuming too much time. While searching information is a major function of $\mathrm{BI}$ tools, enterprise business intelligence systems have started incorporating new functionalities. For example, BI vendors Cognos, Information Builders, and SAS are working with Google to use the Google OneBox with their BI systems (Lawton, 2006). Oracle has acquired Hyperion to expand its capability in financial performance reporting (Sorkin and Merced, 2007). Leveraging on its DB2 database system and data warehousing solutions, IBM is improving access, analysis, and action on company data (IBM, 2006). Incorporating searching and text analysis capabilities in $\mathrm{BI}$ systems can expand access to unstructured data in addition to structured data (Robb, 2007). However, developing such applications is non-trivial and tools that support e-business stakeholder analysis are still rarely found. More challenging functions are to extract from unstructured data meaningful patterns and to visualize these patterns using intuitive metaphors that are pleasing to human eyes. These functions have the potential to further enhance the capabilities of $\mathrm{BI}$ tools, as revealed in the trends of the field. Among the five new trends identified by the Society of Competitive
Intelligence Professionals, three prominent challenges are network analysis, visualization, and visual representation of data (SCIP, 2007).

\section{Web Mining and Information Visualization}

As most $\mathrm{BI}$ resources on the Web are textbased, automated tools and techniques have been developed to exploit textual information. Although text expresses a vast, rich range of information on the Web, it encodes this information in a form that is difficult to decipher automatically (Hearst, 1999). In recent years, Web mining and information visualization emerge as potential solutions (Gregg and Walczak, 2006, Srivastava and Cooley, 2003).

\section{Web Mining}

Web mining is the use of data mining and machine learning techniques to automatically discover and extract information from Web documents and services (Chen and Chau, 2004, Gregg and Walczak, 2006). Given the exponential growth of the Web, it is difficult for any single search engine to provide comprehensive coverage of search results. Meta-searching was shown to be a highly effective method of resource discovery and collection on the Web (Chen et al., 2001). By sending queries to multiple search engines and collating the set of top-ranked results from each search engine, meta-search engines can greatly reduce bias in search results and improve coverage.

To extract information and uncover patterns from Web pages or sites, three categories of Web mining have been identified (Kosala and Blockeel, 2000). Web content mining helps to discover useful information from Web textual and multimedia contents (e.g., Chen et al., 1996, Hurst, 2001, Schatz, 2002, Zamir and Etzioni, 1999). Web structure mining is the analysis of link structures that model the Web (e.g., Brin and Page, 1998, Chakrabarti et al., 1999, Henzinger and Lawrence, 2004, Kleinberg, 1999). Web usage mining studies 
techniques that can predict user behavior while the user interacts with the Web (e.g., Adomavicius and Tuzhilin, 2001, Pazzani, 1999). As businesses increasingly use the Web to share information in the forms of textual Web pages and hyperlinks, Web content mining and Web structure mining have the potential to assist in analysis of the complex business Web site content and structural relationships among sites, leading to more effective and efficient discovery of business intelligence. Unfortunately, research on intelligent Web technologies (e.g., Zhong et al., 2003) seldom addresses the need for $\mathrm{BI}$ discovery on the Web.

\section{Information Visualization}

To alleviate information overload due to a large amount of textual information presented on Web pages and $\mathrm{BI}$ system interface, researchers have proposed frameworks and techniques to create visual displays of such information. Shneiderman proposed a task by data type taxonomy to study the types of data and tasks involved in visual displays of textual information (Shneiderman, 1996). Pfitzner and his colleagues developed a unified taxonomic framework that characterizes information visualization in terms of data, task, skill, and context, as well as a number of dimensions that relate to the input and output hardware, software, and user perceptual abilities (Pfitzner et al., 2003). Zhou and Feiner developed a visual task taxonomy to characterize a number of tasks performed by visualization tools (Zhou and Feiner, 1998). Morse and Lewis proposed and validated a de-featuring approach to evaluate information retrieval interfaces (Morse and Lewis, 2000). Chung and his colleagues developed and validated a methodology in evaluating coordinated event visualization tools involving temporal and spatial information (Chung et al., 2005a). Traditional result list display of search engine belongs to the one-dimensional data type described in the aforementioned frameworks or approaches. While still widely used in many Web search engines and BI systems because of the convenience of presentation, result list allows only limited room for browsing (e.g., scrolling a long list of results). In contrast, data types such as map data, tree data, and network data allow more browsing tasks to be done and support human visual capabilities more effectively. Network visualization, which attracts much attention from researchers in recent years 9e.g., Arquilla and Ronfeldt, 2001, Freeman, 2001, Krebs, 2001), has the promise to enhance analysis and understanding of complicated stakeholder relationships on the Web.

Originated from the fields of sociology and anthropology, network visualization models the behaviors of social actors as nodes and their relationships as links (Freeman, 2001). These nodes and links form social networks that allow identification of patterns and analysis of their structural properties. Recent research has applied social network analysis to different domains. Having observed the rise of network forms of terrorism organizations and strategies, Arquilla and Ronfeldt describe the trend as "netwar" - an emerging model of conflict in which terrorists use network forms of organization and exploit information technology (Arquilla and Ronfeldt, 2001). Krebs relied on open source data to study the terrorist network centering around the 19 hijackers in the 9/11 attacks and identified the chief leaders of the network (Krebs, 2001). Xu and Chen employed hierarchical clustering, multidimensional scaling, and social network analysis techniques to automate criminal network analysis and found that their system could help detect subgroups in criminal networks more efficiently than did untrained subjects (Xu and Chen, 2005). Höpner and Krempel used network visualization techniques and qualitative-historical analysis to discuss the structure, origins and development of a German company network and to analyze the reasons for its recent erosion (Höpner and Krempel, 2003). The network approaches discussed above help understanding the status and evolution of networks. However, they tend to rely on clearly-defined links (such as criminal records and company financial transactions) that cannot be identified easily 
in complicated business stakeholder relationships on the Web. Moreover, none of these approaches have been applied to business stakeholder analysis, although much theoretical work has been done (e.g., Clarkson, 1995, Donaldson and Preston, 1995, Jawahar and McLaughlin, 2001, Mitchell et al., 1997).

\section{A Knowledge Network Approach}

Electronic commerce has transformed the landscape of business environment in recent years. Stakeholders who previously could not affect a firm can now interact with the firm through the Internet. Existing stakeholder theories are limited in the way they accommodate new information technologies. For example, Jawahar and McLaughlin concluded that their descriptive stakeholder theory might be applicable to only traditional businesses but not organizations conducting electronic commerce (Jawahar and McLaughlin, 2001). Adapting stakeholder theory to e-government, Flak and Rose note that despite an extensive body of literature on stakeholder theory, the impact of information technology on stakeholder management is not yet explored (Flak and Rose, 2005). They recommend identifying and classifying stakeholders and improving descriptive stakeholder models to reflect a better understanding between technology and stakeholder relationships. These directions point to a need for integrating IT into traditional stakeholder theories and frameworks, which assume only a manual approach to stakeholder analysis (e.g., Elias and Cavana, 2000, Reid, 2003). Unfortunately, BI systems available nowadays provide insufficient support for advanced analysis and visualization that could potentially illustrate the landscape of a large amount of data collected from the Web. Although business networks and networked organizations have been widely used and studied in recent years, network visualization and analysis approaches have not been applied to stakeholder analysis on the Web. Therefore, we have proposed a knowledge network approach to developing $\mathrm{BI}$ systems that can address the needs.

\section{The Approach}

Our approach consists of the steps for gathering Web data, extracting relevant entities, and analyzing and visualizing these entities. First, it gathers relevant data through meta-searching/meta-spidering, domain spidering, and link searching/spidering. Metasearching/spidering uses keywords as inputs to search multiple Web search engines to collate a set of results (URL links) ranked among the top-ranked results in each engine. Domain spidering uses a set of seed URLs (provided by experts or identified in reputable sources) as starting pages and then automatically fetches the pages linked to the URLs. Link searching/spidering uses URL links as inputs to search engines that support searching for Web pages containing these links in their content. Second, it extracts such entities as textual content and hyperlinks from the data and indexes these entities automatically to provide more contextual information by showing the relationships among entities. An example of entities would be a stakeholder name (e.g., "Microsoft," "IBM") appearing on a Web page. Extracting these entities could help analysts more efficiently understand the major stakeholders involved. Third, it analyzes the extracted entities to discover $\mathrm{BI}$ and to visualize previously hidden patterns through such various techniques as similarity analysis, classification, and network formation. For example, when studying stakeholders of the company named "IBM," an analyst may use the approach to identify stakeholders that share common characteristics, to group them into pre-defined classes, and to form networks of stakeholders to facilitate further understanding.

\section{Prototype Development}

Following the steps in the approach, we have developed a proof-of-concept prototype, Stakeholder Network Visualizer (SNV), for analyzing and visualizing business stakeholder networks on the Web (see Figure 
1 and Figure 2). In the first step, we collected Web pages of business stakeholders of the top 100 knowledge management companies identified by the Knowledge Management World (KM World) Web site (http://www.kmworld.com/), a major Web portal providing news, publications, online resources, and solutions to more than 51,000 subscribers in the knowledge management systems market. To identify such stakeholders, we used the backlink search function of the Google search engine (http://www.google.com/) to search for Web pages having hyperlinks pointing to the companies' Web sites. To illustrate the method, we can type "link: www.siebel.com" in Google's search box to find the Web pages pointing to Siebel's Web site (the host company). According to Ingwersen [Ingwersen, 1998], the hyperlinked pages can be seen to mirror social communication phenomena, such as strategic or tactical referral behavior, and pragmatic or common semantic interest in particular sites on the Web. Therefore, a relationship exists between Siebel and the search results because the hyperlinks imply underlying stakeholder relations with the enterprise.

Among the stakeholder pages of the 100 companies, we randomly selected the stakeholder pages of 9 companies, listed in the menu of screen shot shown in Figure 1, for creating stakeholder networks. In the second step of our approach, the Web pages of the 361 stakeholders of these companies were automatically spidered, parsed, and indexed to extract textual terms and hyperlinks. After filtering out irrelevant and duplicating pages, 283 Web pages were stored in our database for analysis. Each stakeholder page was then manually classified by a $\mathrm{BI}$ expert into one of eleven types based on a modified stakeholder typology adapted from [Reid, 2003]. Having a doctoral degree in information science, the expert has over thirty years of information systems experience in the areas of competitive intelligence, systems analysis, information management.
To analyze and visualize the relationships among stakeholder pages, we performed (in the third step of our approach) similarity analysis, stakeholder placement using multidimensional scaling, and network formation. The similarity calculation tried to assign a high similarity score to a pair of Web pages that have similar textual terms, are referencing each other via hyperlinks, and have many other Web pages referencing them together. We used the following formula to calculate the similarity (ranging from 0 to 1 ):

Similarity between page $\mathrm{i}$ and page $\mathrm{j}=$

$$
W_{i j}=\alpha \frac{A_{i j}}{\|A\|_{2}}+\beta \frac{S_{i j}}{\|S\|_{2}}+(1-\alpha-\beta) \frac{C_{i j}}{\|C\|_{2}}
$$

Where $A, S$, and $C$ are matrices for $A_{i j}, S_{i j}$, and $C_{i j}$ respectively. $\alpha$ and $\beta$ are parameters between 0 and 1 , and $0 \leq \alpha+\beta \leq 1\left(A_{i j}=1\right.$ if page $i$ has a hyperlink referencing page $j, A_{i j}$ $=0$ otherwise; $C_{i j}=$ number of Web pages referencing both page $i$ and page $j$ (cocitation matrix); $S_{i j}=$ Content similarity (asymmetric) score between page $i$ and page $j$ (Chen and Lynch, 1992)). Based on empirical testing, we chose the parameters of $\alpha$ and $\beta$ to be 0.2 and 0.7 respectively. These weights reflected the fact that most materials on the stakeholder Web pages were represented by textual content and can be adjusted by the system developers. Hyperlinks were the next most frequently used medium on these pages, which were co-cited sparingly, leading to a low weight assigned to co-citation information.

After the calculation, the relationships among stakeholder pages were then represented by networks in which nodes representing stakeholders were placed on a twodimensional space using multidimensional scaling (MDS) visualization, which provided a high-level picture of all the stakeholders and their relationships. We used MDS to transform a high-dimensional similarity matrix to a set of two-dimensional coordinates (Young, 1987), where proximity between the 
nodes reflects similarity. While other visualization techniques might have been applicable, MDS was suitable for the current data structure and provided a vivid picture summarizing stakeholders' relationships.

In Figure 1 and Figure 2, we show the user interface of the prototype and a stakeholder network of a company named Fujitsu Software. A user can click on one of the nine listed companies listed in Figure 1 to choose the stakeholder network to be displayed. Then the user can view the network as shown in Figure 2. The links of the network represent similarity linkages among stakeholders. These linkages were assigned weights same as the similarity scores calculated above. In the network, the stakeholders of Fujitsu Software appear as nodes and the lines connect pairs of similar nodes. A user can click on a node to display the title, summary, and URL of that stakeholder.

\section{A Scenario of BI Analysis}

To provide a realistic picture of stakeholder network analysis, we illustrate it with a scenario of $\mathrm{BI}$ analysis and compare between a traditional manual approach and an approach using Stakeholder Network Visualizer. A business analyst of Siebel (http://www.siebel.com/) would like to formulate a strategic plan on gathering business intelligence and managing various interested parties of the company. He wants to know who have an interest in the company, what type of interest it belongs to, and how this interest relates to the interests of other stakeholders. His questions may include: "Can we visualize the complex relationships between our company and various other partners in our field?" "How can we identify various groups having shared interests with us? What are the relationships between our company and these groups?" "How do the media and governments relate to our company?" A manual approach to this analysis would be to gather information from many sources, such as magazines, newspapers, government publications, and expert advices. Then the analyst manually digests all the collected information. He may use Web search engines to help but he needs to formulate all search queries and to choose search strategies based on his own knowledge. After getting the information, he needs to manually classify the various parties into different stakeholder types to understand their interests on the company.

Alternatively, an approach using SNV would be to obtain potential stakeholder Web pages automatically through Web mining methods, to extract entities from these pages and to index them, and to automatically create networks of the stakeholders. For example, from a stakeholder's hyperlink (http://www.cic.com/partners/), the analyst identifies that Communication Intelligence Corporation $(\mathrm{ClC})$ partners with Siebel to integrate e-signature technology for sample delivery of regulated drugs. Based on the displayed network relationships and the Web page clues, the analyst learns that CRM Daily is a Web portal that has reported Siebel's Universal Application Network (http://www.crm-daily.com/perl/storyl

20142.html). Also, the analyst finds that Siebel is one of over 400 OEM customers of Hummingbird, a leading enterprise software solution provider in the United States (http://www.hummingbird.com/solutions/oem/ customers.html). These results would have been obtained less efficiently and less accurately had the analyst used a traditional manual approach. Moreover, knowing these relationships would enable analysts and managers of Siebel to plan better for addressing stakeholders' needs and to capitalize on the relationships. For example, Siebel's analyst can further evaluate the performance of Hummingbird's software solutions to see whether they should switch to another vendor or seek outsourcing from other countries. Also, the analyst can further study CRM Daily to find other Siebel's competitors that may threaten Siebel's market-leading position. Similarly, the analyst can visit CIC's Web site to study its other partners who may compete with or have potential future relationship with Siebel. 
These answers may help Siebel to better understand their competitive environment and to locate business opportunities that would otherwise be lost.
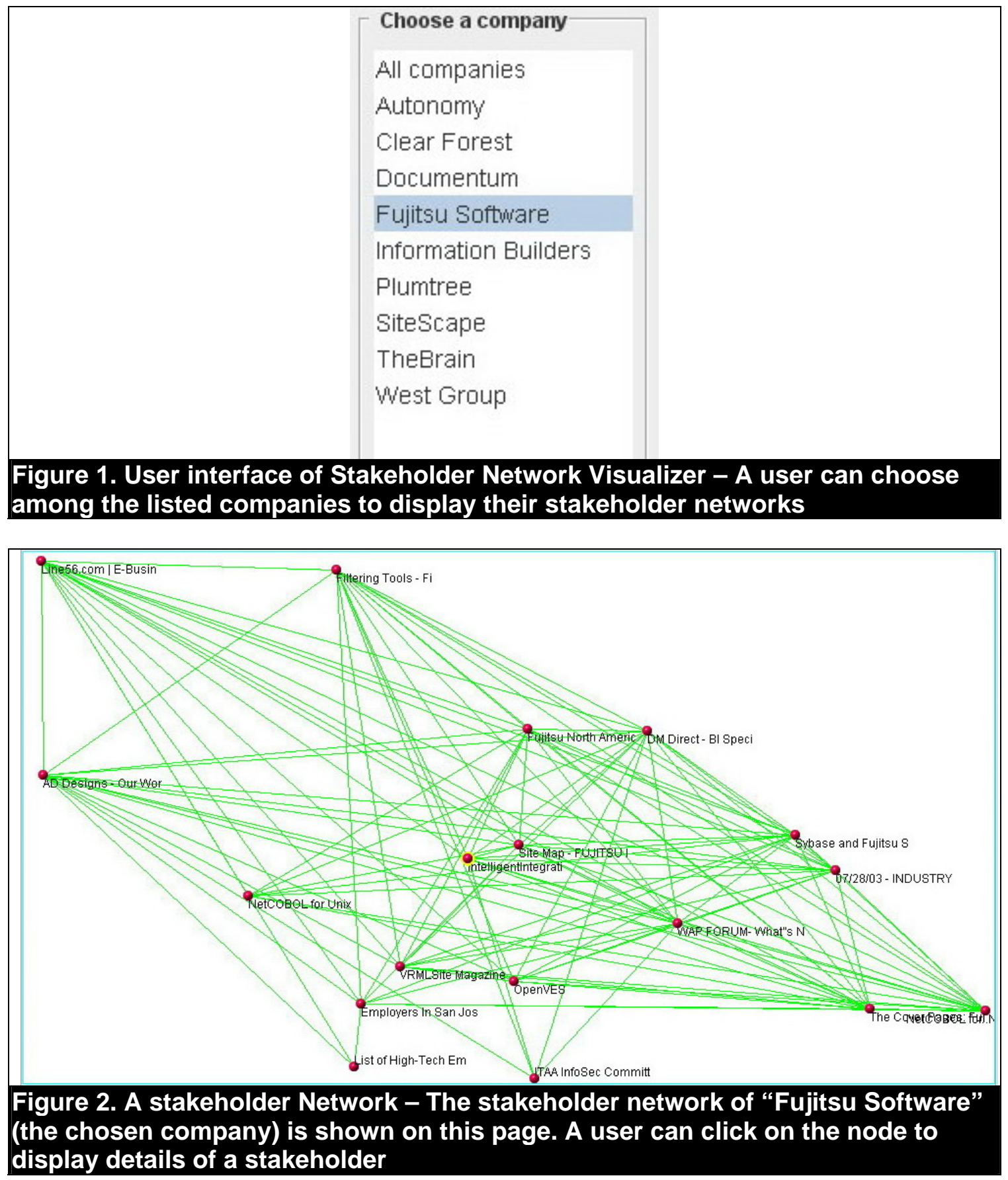

\section{System Evaluation and Experimental Design}

This section describes the evaluation methodology and design of an experiment conducted to evaluate the usability of SNV in helping human users to obtain business intelligence on the Web. We compared SNV with a traditional method, in which subjects obtained $\mathrm{BI}$ manually by searching and browsing company Web sites. Table 2 provides a comparison of the two methods. Because traditional methods are weak at 
efficiently supporting collection and analysis of high-quality $\mathrm{BI}$, we chose to study the efficiency and information quality of the $\mathrm{BI}$ obtained, and perceived usability the methods. To increase the external validity of the results, we invited both student and business practitioners to participate as voluntary subjects in the experiment. In the following, we describe the experimental design, hypothesis testing, and performance measures.

\section{Experimental Design}

Based on the attributes of our prototype and the nature of intelligence analysis tasks used in a previous study (Chung et al., 2005a), we designed different types of experimental tasks that focused on the functions of comparing, ranking, and clustering. A sample task was "Identify the stakeholders named 'Autonomy (Powered by Genesys Conferencing)' and 'California Computer.' Which one has more connections with other stakeholders?" Also, a subject may be asked to rank a number of stakeholders in descending order of the strength of their relationship with another stakeholder. The subject may need to find clusters among the displayed networks. A BI expert verified that all the tasks used in this experiment were appropriate business analysis tasks. This expert is CEO of two publicly-traded companies in North America and had over 26 years' experience in business development, raising capital, negotiations, finance, and strategic planning. He was Vice President of Business Development for the Gallup Organization, a leading market research firm.

\begin{tabular}{|l|l|l|}
\hline \multicolumn{3}{|l|}{ Table 2. Comparing between a Traditional Method and SNV } \\
\hline Dimension & Traditional Method & Stakeholder Network Visualizer \\
\hline Display mode & Linear (textual lists) & Network (links and nodes) \\
\hline Visual appeal & Low & High \\
\hline $\begin{array}{l}\text { Amount of details } \\
\text { presented }\end{array}$ & $\begin{array}{l}\text { Complete textual content, little } \\
\text { aggregate information }\end{array}$ & $\begin{array}{l}\text { Aggregated content, little textual } \\
\text { information }\end{array}$ \\
\hline $\begin{array}{l}\text { Knowledge needed to } \\
\text { comprehend the } \\
\text { content }\end{array}$ & $\begin{array}{l}\text { Company background, terms, } \\
\text { stakeholder relationships, } \\
\text { jargons, etc. }\end{array}$ & $\begin{array}{l}\text { Company names, abstraction in a } \\
\text { network display }\end{array}$ \\
\hline $\begin{array}{l}\text { Skills needed in using } \\
\text { the method }\end{array}$ & $\begin{array}{l}\text { Basic Internet searching and } \\
\text { browsing skills }\end{array}$ & $\begin{array}{l}\text { Skills in manipulating network } \\
\text { components using a computer }\end{array}$ \\
\hline
\end{tabular}

We invited both business practitioners and students to serve as subjects. Results from these two groups of subjects were analyzed separately. In the student group, forty-seven undergraduate students of a senior-level database management class at a university in the United States participated as volunteer subjects. In the practitioner group, fifteen business practitioners who were enrolled in a part-time MBA program served as volunteer subjects. Having an average of 8.1 years' working experience, these subjects represented such business professionals as IT managers, e-commerce CEO, project leader, trade compliance specialist, business coordinator, lab managers, production engineering supervisor, and so on. Each subject used
SNV and a traditional method of $\mathrm{BI}$ analysis to perform the assigned experimental tasks. When using the traditional method, the subject was given a list of stakeholders (shown on screen) and a computer with Internet connection to search and browse stakeholder Web pages. Figure 3 shows screen shots of the index page of the nine companies (upper right of Figure 3 ) and the stakeholders of ClearForest, one of those nine companies (lower left of Figure 3). Subjects were allowed to visit the sites of these stakeholders and, if they needed further information, they could search and browse any other sites they knew of (such as search engines and business directories). This method is typically used by business analysts to identify business stakeholders 
and to study their relationships. When using SNV, the subject used only the tool to study stakeholder information.

In the one-hour experiment, we introduced the two methods (SNV and the traditional method) to each subject and randomly assigned two different scenarios to evaluate the methods in two sections. A scenario included three tasks (compare, rank, and cluster) related to a company and its stakeholders. The two companies appearing in the two sections were Sitescape and Autonomy that were randomly selected from the list of companies shown in Figure 1. Before a subject used a method to perform the tasks, the experimenter showed him or her how to perform sample experimental tasks using that method. Written instructions also were given to the subject for reference.
Because the three tasks in each scenario might be related to each other, we allowed the subject to work on these tasks in their preferred sequence. In other words, the subject could revisit a question in the same scenario after working on another question. However, the subject was not allowed to revisit a section after completing all tasks in that section. The order in which the methods were used in the scenarios was randomly assigned to avoid bias owing to sequence of use. Each subject provided in a post-section questionnaire ratings and comments on the method right after using it so as to ensure a fresh memory of the method's features. The experimenter recorded all verbal comments or behavioral observations that were later analyzed using protocol analysis (Ericsson and Simon, 1993).

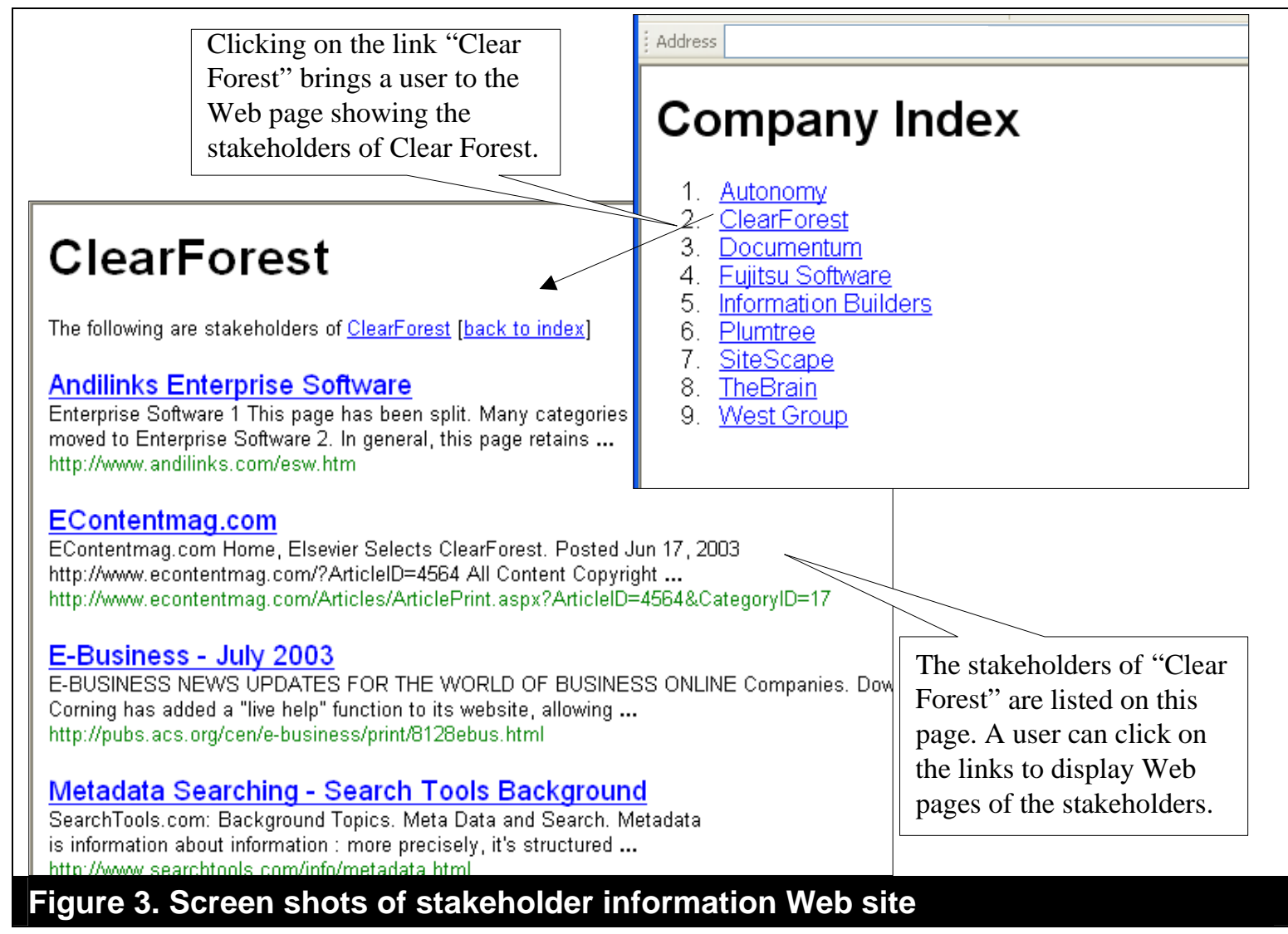

After finishing the two sections, a subject filled in a post-study questionnaire to compare the two methods and to provide further comments. A seven-point Likert scale was used in these ratings. To measure information quality, we modified 
the 16-dimension construct developed in [Wang and Strong, 1996] by dropping the "security" dimension that was not relevant because the information provided by the methods is already public. Because the remaining 15 dimensions may have different impact on information quality in our chosen domain, we invited the same BI expert who helped verify the appropriateness of the experimental tasks to provide ratings on the relative importance of different dimensions (see Table 3). As had been done in (Marshall et al., 2004), we summarized the 15 dimensions of information quality into 3 categories: presentation quality and clarity, coverage and reliability, and usability and analysis quality. The mean rating for each category was obtained by multiplying the weighted expert rating with the average score of that category.

We also asked each subject to provide ratings on several attributes of each method, including usefulness, ease of use, and information display and interface design, based on the items in the questionnaires developed in (Davis, 1989) and [Lewis, 1995]. The subjects also provided demographic information, which was kept confidential in accordance with the Institutional Review Board Guidebook (Penslar, 2001).

\section{Hypothesis Setting}

Because SNV was designed and developed based on a comprehensive methodology that encompasses collection, extraction, analysis, and visualization of business information, we anticipated that SNV would provide higher quality of $\mathrm{BI}$ and higher usability than those of the traditional method and that SNV would help users perform BI tasks more efficiently. Therefore, we established the following hypotheses:

H1: SNV achieves a higher efficiency than a traditional method.

H2: SNV provides higher information quality (in terms of presentation quality and clarity, coverage and reliability, and usability and analysis capability) than a traditional method.

H3: SNV obtains higher overall satisfaction scores than a traditional method.

To test $\mathrm{H} 1$, we compared the amounts of time taken to complete the tasks using the two methods. To test $\mathrm{H} 2$ and $\mathrm{H} 3$, we compared subjects' ratings on the aforementioned aspects. As each subject was asked to perform similar tasks using SNV and a traditional method, we used a one-factor repeated-measures design, which gives greater precision than designs that employ only between-subjects factors (Myers and Well, 1995).

We recorded the time the subject spent on using each method to measure the efficiency of the method. Usability and information quality were measured by subjects' ratings on a seven-point Likert Scale.

\section{Experimental Results and Discussions}

In this section, we report and discuss the results of our user evaluation study. Table 3 summarizes the means and standard deviations of various performance measures. Table 4 shows the $p$-values and results of testing various hypotheses using pairwise $t$-tests on the sample means. Table 6 summarizes subjects' demographic profiles. 


\begin{tabular}{|c|c|c|}
\hline Dimension & Definition & Expert Rating* \\
\hline \multicolumn{3}{|c|}{ Presentation quality and clarity } \\
\hline Accessibility & $\begin{array}{l}\text { The extent to which information is available, or easily } \\
\text { and quickly retrievable }\end{array}$ & 3 \\
\hline Concise Representation & $\begin{array}{l}\text { The extent to which information is compactly } \\
\text { represented }\end{array}$ & 3 \\
\hline $\begin{array}{l}\text { Consistent } \\
\text { Representation }\end{array}$ & $\begin{array}{l}\text { The extent to which information is presented in the } \\
\text { same format }\end{array}$ & 3 \\
\hline Ease of Manipulation & $\begin{array}{l}\text { The extent to which information is easy to manipulate } \\
\text { and apply to different tasks }\end{array}$ & 3 \\
\hline Interpretability & $\begin{array}{l}\text { The extent to which information is in appropriate } \\
\text { languages, symbols, and units, and the definitions are } \\
\text { clear }\end{array}$ & 2 \\
\hline \multicolumn{3}{|l|}{ Coverage and reliability } \\
\hline $\begin{array}{l}\text { Appropriate amount of } \\
\text { information }\end{array}$ & $\begin{array}{l}\text { The extent to which the volume of information is } \\
\text { appropriate for the task at hand }\end{array}$ & 2 \\
\hline Believability & $\begin{array}{l}\text { The extent to which information is regarded as true } \\
\text { and credible }\end{array}$ & 2 \\
\hline Completeness & $\begin{array}{l}\text { The extent to which information is not missing and is } \\
\text { of sufficient breadth and depth for the task at hand }\end{array}$ & 3 \\
\hline Free-of-error & The extent to which information is correct and reliable & 2 \\
\hline Objectivity & $\begin{array}{l}\text { The extent to which information is unbiased, } \\
\text { unprejudiced, and impartial }\end{array}$ & 2 \\
\hline \multicolumn{3}{|c|}{ Usability and analysis quality } \\
\hline Relevancy & $\begin{array}{l}\text { The extent to which information is applicable and } \\
\text { helpful for the task at hand }\end{array}$ & 3 \\
\hline Reputation & $\begin{array}{l}\text { The extent to which information is highly regarded in } \\
\text { terms of its source or content }\end{array}$ & 3 \\
\hline Timeliness & $\begin{array}{l}\text { The extent to which information is sufficiently up-to- } \\
\text { date for the task at hand }\end{array}$ & 3 \\
\hline Understandability & $\begin{array}{l}\text { The extent to which information is easily } \\
\text { comprehended }\end{array}$ & 3 \\
\hline Value-Added & $\begin{array}{l}\text { The extent to which information is beneficial and } \\
\text { provides advantages from its use }\end{array}$ & 3 \\
\hline
\end{tabular}

* Expert rating: 3 = extremely important, 2 = very important, 1 = important

\section{Efficiency of the Methods}

We found that SNV achieved a significantly higher efficiency than the traditional method. Using SNV, the student subjects spent an average of 15.2 minutes to finish the tasks while the practitioner subjects spent only 11.4 minutes. However, using the traditional method, both groups of subjects spent a significantly longer time on average to complete the tasks (students: 27.5 minutes; practitioners: 21.9 minutes). We believe that the visualization provided by SNV enabled the subjects to complete the tasks more efficiently, saving their time and reducing their effort. SNV's capabilities in summarizing large amounts of stakeholder information and in presenting such information in a meaningful network format helped the subjects to complete the tasks efficiently. In contrast, subjects had to manually understand and digest the materials obtained by the traditional method. Therefore, $H 1$ was supported.

\section{BI Quality}

Subjects in both groups rated the quality of $\mathrm{BI}$ obtained from SNV to be significantly higher than that of the traditional method, showing that the information provided by SNV enabled them to perform the task more 
effectively. Among all three categories of dimensions of information quality (see Table 3 for the three categories of information quality), SNV got significantly better mean ratings. We believe that SNV's comprehensive data collection contributed to better information coverage and that SNV's visualization support contributed to a better presentation quality and analysis quality. Therefore, we conclude that $\mathrm{H} 2$ was supported.

\section{Table 4. Means and Standard Deviations of Different Measures}

\begin{tabular}{|c|c|c|c|c|c|c|c|c|}
\hline \multirow{3}{*}{ Measure } & \multicolumn{4}{|c|}{ Students } & \multicolumn{4}{|c|}{ Practitioners } \\
\hline & \multicolumn{2}{|c|}{ SNV } & \multicolumn{2}{|c|}{ Traditional Method } & \multicolumn{2}{|c|}{ SNV } & \multicolumn{2}{|c|}{ Traditional Method } \\
\hline & Mean & S.D. & Mean & S.D. & Mean & S.D. & Mean & S.D. \\
\hline Efficiency (in minutes) & 15.15 & 9.41 & 27.5 & 19.4 & 11.42 & 7.84 & 21.92 & 7.60 \\
\hline Information Quality (Overall) & 2.28 & 0.85 & 3.40 & 1.38 & 2.52 & 0.88 & 4.01 & 1.26 \\
\hline $\begin{array}{l}\text { - Presentation quality and } \\
\text { clarity }\end{array}$ & 2.23 & 0.89 & 3.47 & 1.38 & 2.07 & 0.89 & 4.08 & 1.39 \\
\hline - Coverage and reliability & 2.39 & 0.93 & 3.31 & 1.45 & 2.78 & 0.94 & 4.04 & 1.26 \\
\hline $\begin{array}{l}\text { - Usability and analysis } \\
\text { quality }\end{array}$ & 2.21 & 0.92 & 3.45 & 1.47 & 2.68 & 1.07 & 3.90 & 1.56 \\
\hline Overall satisfaction & 2.28 & 1.12 & 4.26 & 2.03 & 2.31 & 1.16 & 5.08 & 1.22 \\
\hline - Usefulness & 2.41 & 1.05 & 4.73 & 1.72 & 1.97 & 0.92 & 5.02 & 1.73 \\
\hline - Ease of use & 2.35 & 1.02 & 3.88 & 1.63 & 2.16 & 0.94 & 4.17 & 1.28 \\
\hline $\begin{array}{l}\text { - Information display and } \\
\text { interface design }\end{array}$ & 2.53 & 0.97 & 4.23 & 1.56 & || 2.53 & 0.91 & 4.40 & 1.29 \\
\hline
\end{tabular}

Table 5. $p$-values of testing various hypotheses (alpha error* $=\mathbf{0 . 0 5}$ )

\begin{tabular}{|c|c|c|c|c|}
\hline Hypothesis & Measure & Students & Practitioners & Result \\
\hline $\mathrm{H} 1$ & Efficiency & $0.000^{\star}$ & $0.003^{*}$ & Supported \\
\hline \multirow[t]{4}{*}{$\mathrm{H} 2$} & Information quality (overall) & $0.000^{*}$ & $0.005^{\star}$ & \multirow[t]{4}{*}{ Supported } \\
\hline & Presentation quality and clarity & $0.000^{*}$ & $0.001^{*}$ & \\
\hline & Coverage and reliability & $0.000^{*}$ & $0.014^{\star}$ & \\
\hline & Usability and analysis quality & $0.000^{*}$ & $0.040^{\star}$ & \\
\hline \multirow[t]{4}{*}{ H3 } & Satisfaction & $0.000^{*}$ & $0.000^{*}$ & \multirow[t]{4}{*}{ Supported } \\
\hline & Usefulness & $0.000^{\star}$ & $0.000^{*}$ & \\
\hline & Ease of use & $0.000^{*}$ & $0.000^{*}$ & \\
\hline & $\begin{array}{l}\text { Information display and interface } \\
\text { design }\end{array}$ & $0.000^{\star}$ & $0.000^{*}$ & \\
\hline
\end{tabular}

\begin{tabular}{|c|c|c|}
\hline $\begin{array}{l}\text { Demographic } \\
\text { information }\end{array}$ & Students (total: 47) & Practitioners (total: 15) \\
\hline Education & $\begin{array}{l}\text { Undergraduate (32), associate } \\
\text { degree earned (10), bachelor earned } \\
(3), \text { master earned (2) }\end{array}$ & $\begin{array}{l}\text { Bachelor earned (11), master } \\
\text { earned (4) }\end{array}$ \\
\hline Age range & $\begin{array}{l}18-25(28), 26-30(8), 31-35(5), 41- \\
50(3), 51-60(2), 60 \text { or above (1) }\end{array}$ & $\begin{array}{l}18-25(4), 26-30(5), 31-35(4), \\
36-40(1), 41-50(1)\end{array}$ \\
\hline Gender & Female (19), Male (28) & Female (9), Male (6) \\
\hline $\begin{array}{l}\text { Hours of using computer } \\
\text { per week }\end{array}$ & $\begin{array}{l}<5(6), 5-10(6), 10-15(11), 15-20 \\
(2), 20-25(7), 25-30(1), 30-35(3),> \\
35(11)\end{array}$ & $\begin{array}{l}10-15(2), 15-20(3), 20-25(1), \\
25-30(2), 30-35(2),>35(5)\end{array}$ \\
\hline
\end{tabular}




\section{User Satisfaction and Comments}

As shown in Table 3 and Table 4, subjects' ratings of SNV on usefulness, ease of use, information display and interface design, and overall satisfaction were all significantly better than those of the traditional method. These encouraging results demonstrate the high usability of SNV in supporting $\mathrm{BI}$ analysis. In particular, SNV obtained a very favorable rating on "usefulness" in the practitioner group, showing a high promise that SNV would be very useful in real-world $\mathrm{BI}$ analysis. The large differences in ratings between the two methods also reflected a strong preference toward a user-friendly and visually-pleasing method such as SNV. We conclude that $H 3$ was supported.

In addition, subjects commented positively on SNV. Their written comments revealed that SNV was very easy to use and helped them perform the tasks. For example, a subject in the practitioner group said that SNV was "easy to use, easy to manipulate, (and) easy to understand, (and it was) easy to see almost all the connections completely." Another subject in that group said: "it is easy to manipulate and check the relationship with the nodes" and "the information given is clear." Subjects also found the network interface visually pleasing and helpful to locate relevant information. For instance, a student subject said: "The good thing about the system is that it is very complete. It provides an efficient mechanism to correlate the relation between stakeholders." Another student subject said that "it is excellent to identify relationships. It is easy to find which node has more connections with other nodes." Subjects liked the fact that SNV helped them save their time and reduce their effort, as a student subject said: "I like when you click a node you give some info about it in the bottom box." Another student subject commented that it was "easy to understand and manipulate information (and) saves a lot of time."
When asked to comment on the design style of SNV, some subjects would like to have more directions and guidance to use the system because it was new to them. Others expressed a desire to have more information about the stakeholders and to have a text search function like that provided in a Web search engine. To address these comments, the system will require significant changes in the user interface and integration with the Web searching and browsing functions. In addition, more efforts are needed to increase precision, to balance between information display and showing cluttered networks, and to increase the number of functions.

In contrast, the subjects were dissatisfied with the traditional method of $\mathrm{BI}$ analysis (Web searching and browsing) because of the difficulty in finding stakeholder information and the inconvenience of identifying stakeholder relationships. For example, a subject in the practitioner group said: "it is very difficult to find stakeholder information (and) connections strength of relationships." Another subject said that this method was "very difficult to understand, very time consuming, (and) not very pleasant to look at." Another subject complained that there was "too much information" and it was "difficult to find specific information." Many subjects complained about the lack of organization of information. For instance, a student subject said that the "information is hard to compare, (and) there is no sense of organization." In particular, they had much difficulty finding relationships among the stakeholders. One subject said that it was "very hard to find links between shareholders" and another subject even considered this method "absolutely worthless" when frustrated with the difficulty. Nevertheless, some subjects liked the fact that they were familiar with Web searching and browsing and they could get as much information as they wanted. 


\section{Discussions and Implications}

The encouraging results from our experiment demonstrate a high usability of SNV. We believe that the system's high information quality, comprehensiveness in information collection, and useful functionality for $\mathrm{BI}$ analysis and visualization contributed to the results. These important components can be helpful to users who need to obtain $\mathrm{BI}$ from widely scattered information sources on the Web and to analyze complicated stakeholder relationships appearing in a multitude of Web sites. Given the importance of Internet in today's global economy, this research has shed light on research and practice about collecting and analyzing $\mathrm{BI}$ on the Web.

Addressing the sparseness of $\mathrm{BI}$ research in the literature [Negash, 2004] and the lack of integration of IT into traditional stakeholder theories and frameworks (Jawahar and McLaughlin, 2001), this research provides new impetus for $\mathrm{BI}$ research and the study of stakeholder theory. Rapidly emerging issues such as $\mathrm{BI}$ system design, information quality of $\mathrm{BI}$, use of information visualization in business analysis, and human perception of different stakeholder analysis methods have been explored in this study. For research in $\mathrm{BI}$ and stakeholder theory, this study has provided a thorough review of traditional stakeholder theories and has reported results comparing a traditional stakeholder analysis method with a new method that has integrated IT into the analysis. New findings from the experiment will contribute to such disciplines as $\mathrm{BI}$ research, human-computer interaction, and information visualization.

\section{Conclusions and Future Directions}

Business intelligence has been identified as a strategic weapon in today's global competitive environment (Blenkhorn and Fleisher, 2005, Gilad, 2004). The proliferation of the Internet in recent years further fuels the demand for BI. Much information on the Web, though often in large volume, fails to address the need of business analysis and to provide highquality $\mathrm{BI}$. This research explored various issues in $\mathrm{BI}$ analysis, stakeholder theory, and system design by proposing a new approach for $\mathrm{BI}$ system design and empirically evaluating a prototype, called Stakeholder Network Visualizer, designed and developed based on the approach. Results of an experiment involving business practitioners and students show that SNV significantly outperformed a traditional method of $\mathrm{BI}$ analysis in terms of efficiency, information quality, and user satisfaction. Subjects very much preferred SNV to the traditional method and provided many positive comments on SNV. We conclude that the proposed approach is promising in enhancing the quality of $\mathrm{BI}$. This research thus contributes to (1) reviewing the literature of $\mathrm{BI}$ research and stakeholder theory, (2) providing a proof-of-concept prototype for $\mathrm{BI}$ analysis, and (3) reporting the empirical results of an experiment comparing the prototype with a traditional method using business practitioners and students as subjects.

Our work in this research was limited in several ways. As a research prototype, SNV's functionality and stability are generally not as matured as other commercial tools and Internet search engines. This explains why some subjects would like to see addition of search function found in search engines and removal of system errors. Besides, we are limited by the scarce prior work on $\mathrm{BI}$ research, especially on system design and evaluation. This prevented a more comprehensive review of the topic that possibly could offer better criteria for developing the approach and prototype. The use of Google alone in identifying stakeholders limited the scope of data collection. As for the experimental evaluation, enlarging the sample of business practitioners could have increased the statistical confidence of the experimental results. 
Several future research directions are promising. As there are different types of stakeholders that companies must manage, the type of prototype developed in this research must be extended to address the needs of specific stakeholders rather than all stakeholders in general. For example, customers' satisfaction and loyalty are often considered the critical success factors for businesses. With widespread use of electronic commerce, businesses face challenges of managing customers who may come from any location in the world and have vastly different expectations. Designing $\mathrm{BI}$ systems that can properly collect and analyze information of existing and potential customers may help expand business opportunities. Another type of stakeholder that presents great opportunities to businesses is partner. BI systems that exploit partnership networks and properly summarize information can help devise competitive strategy. Because public infrastructures often affect a business's profitability and long-term stability, designing $\mathrm{BI}$ systems that focus on government information would help businesses understand public service better and hence leverage the opportunities for doing business. As information of different types of stakeholders is modeled and integrated into system design, traditional stakeholder theory can be studied and possibly revised to incorporate new information and relationships identified by new technologies. This change affords new theoretical development in $\mathrm{BI}$ and stakeholder research. Results of evaluating newly designed systems also will enhance the knowledge base of $\mathrm{BI}$ research.

\section{Acknowledgments}

We thank the subjects and expert who participated in the experiment. We also thank the editor and the anonymous reviewers for their comments and suggestions. 


\section{References}

Adomavicius, G. and A. Tuzhilin (2001) "Using data mining methods to build customer profiles," IEEE Computer 34 (2), pp. 74-82.

Arquilla, J. and D. Ronfeldt (eds.) (2001) Networks and Netwars: the Future of Terror, Crime, and Militancy, California: Rand.

Barnard, C. (1938) The Function of the Executive. Cambridge: Harvard University Press.

Berle, A. and G. Means (1932) The Modern Corporation and Private Property. New York: Commerce Clearing House.

Blenkhorn, D. L. and C. S. Fleisher (eds.) (2005) Competitive Intelligence and Global Business, Westport, CT: Praeger.

Bowman, C. M., P. B. Danzig, U. Manber, and F. Schwartz (1994) "Scalable Internet resource discovery: research problems and approaches," Communications of the ACM (37) 8, pp. 98-107.

Brin, S. and L. Page. (1998) The anatomy of a large-scale hypertextual Web search engine. Proceedings of the 7th International WWW Conference, Brisbane, Australia, 1998.

Carvalho, R. and M. Ferreira (2001) "Using information technology to support knowledge conversion processes," Information Research (7) 1, http://informationr.net/ir/7-

1/paper118.html (current Sept. 2001)

Chakrabarti, S., B. Dom, K. S., P. Raghavan et al. (1999) "Mining the Web's link structure," IEEE Computer 32 (8), pp. 60-67.

Chen, H. and M. Chau (2004) Web mining: machine learning for Web applications, in, vol. $38 \mathrm{M}$. E. Williams (Ed.) Annual Review of Information Science and Technology (ARIST), Medford, $\mathrm{NJ}$ : Information Today, Inc., pp. 289-329.

Chen, H., H. Fan, M. Chau, and D. Zeng (2001) "MetaSpider: meta-searching and categorization on the Web," Journal of the American Society for Information Science and Technology 52 (13), pp. 1134-1147.

Chen, H. and K. J. Lynch (1992) "Automatic construction of networks of concepts characterizing document databases," IEEE Transactions on Systems, Man, and Cybernetics 22 (5), pp. 885-902.

Chen, H., C. Schuffels, and R. Orwig (1996) "Internet categorization and search: a self-organizing approach," Journal of Visual Communication and Image Representation 7 (1), pp. 88-102.

Choo, C. W. (1998) The Knowing Organization. Oxford: Oxford University Press.

Chung, W. (2006) "Studying information seeking in the non-English Web: An experiment on a Spanish business Web portal," International Journal of Human-Computer Studies 64 (9), pp. 811-829.

Chung, W., H. Chen, L. G. Chaboya, C. O'Toole et al. (2005a) "Evaluating event visualization: a usability study of COPLINK Spatio-Temporal Visualizer," International Journal of Human-Computer Studies 62 (1), pp. 127-157.

Chung, W., H. Chen, and J. F. Nunamaker (2005b) "A visual framework for knowledge discovery on the Web: An empirical study on business intelligence exploration," Journal of Management Information Systems 21 (4), pp. 57-84.

Clarkson, M. B. E. (1995) "A stakeholder framework for analyzing and evaluating corporate social performance," Academy of Management Review 20 (1), pp. 92117.

Cronin, B. (2000) "Strategic intelligence and networked business," Journal of Information Science 26, pp. 133-138.

Davies, P. H. J. (2002) Intelligence, information technology, and information warfare, in, vol. $36 \mathrm{M}$. E. 
Williams (Ed.) Annual Review of Information Science and Technology, Medford, NJ: Information Today, Inc., pp. 313-352.

Davis, F. D. (1989) "Perceived usefulness, perceived ease of use, and user acceptance of information technology," MIS Quarterly 13 (3), pp. 319-340.

Donaldson, T. and L. E. Preston (1995) "The Stakeholder Theory of the Corporation: Concepts, Evidence and Implications," Academy of Management Review 20 (1), pp. 6591.

Elias, A. A. and R. Y. Cavana. (2000) Stakeholder Analysis for Systems Thinking and Modeling. Proceedings of the 35th Annual Conference of the Operational Research Society of New Zealand, Wellington, New Zealand, 2000.

Ericsson, K. A. and H. A. Simon (1993) Protocol analysis: verbal reports as data. Cambridge, MA: MIT Press.

Flak, L. S. and J. Rose (2005) "Stakeholder governance: adapting stakeholder theory to e-government," Communication of the Association for Information Systems 16 (31), pp. 642-664.

Fleisher, C. S. and D. L. Blenkhorn (eds.) (2003) Controversies in competitive intelligence: the enduring issues, Westport, CT: Praeger.

Freeman, E. (1984) Strategic Management: A Stakeholder Approach. Marshfield, MA: Pitman.

Freeman, L. (2001) "Visualizing social networks," Journal of Social Structure 1 (1).

Fuld, L. M. and A. Singh (2005) The Competitive Intelligence Software Survey 2005: A Technology Tale of Career Risk. Cambridge, MA, USA: Fuld \& Company Inc.

Gilad, B. (2004) Early Warning: Using Competitive Intelligence to Anticipate Market Shifts, Control Risk, and Create Powerful Strategies. New
York: American Management Association.

Gregg, D. G. and S. Walczak (2006) "Adaptive Web information extraction," Communications of the ACM 49 (5), pp. 78-84.

Handfield, R. (2006) Supply Market Intelligence: A Managerial Handbook for Building Sourcing Strategies. Boca Raton, FL: Auerbach Publications.

Hearst, M. A. (1999) Untangling text data mining. Proceedings of the 37th Annual Meeting of the Association for Computational Linguistics, College Park, MD, 1999.

Henzinger, M. R. and S. Lawrence (2004) "Extracting knowledge from the World Wide Web," Proceedings of the National Academy of Sciences of the United States of America.

Höpner, M. and L. Krempel. (2003) The politics of the German company network. Planck Institute for the Study of Societies.

Hurd, M. and L. Nyberg (2004) The Value Factor: How Global Leaders Use Information for Growth and Competitive Advantage. Princeton, $\mathrm{NJ}$ : Bloomberg Press.

Hurst, M. (2001) Layout and language: challenges for table understanding on the Web. Proceedings of the 1st International Workshop on Web Document Analysis, Seattle, WA, USA, 2001, pp. 27-30.

IBM (2006) Data Warehousing and Business Intelligence: http://www306.ibm.com/software/data/db2bi/.

Ingwersen, P. (1998) "The Calculation of Web Impact Factors," Journal of Documentation (54) 2, pp. 236-243.

Jawahar, I. M. and G. L. McLaughlin (2001) "Toward a descriptive stakeholder theory: an organizational life cycle approach," Academy of Management Review 26 (3), pp. 397-414.

Kassler, H. and M. A. Sandman (2000) Chapter 6: Information resources for intelligence, in J. P. Miller (Ed.) 
Millennium Intelligence: Understanding and Conducting Competitive Intelligence in the Digital Age, Medford, NJ: CyberAge Books, pp. 97-132.

Kleinberg, J. (1999) "Authoritative sources in a hyperlinked environment," Journal of the Association of Computing Machinery 46 (5), pp. 604-632.

Kosala, R. and H. Blockeel (2000) "Web mining research: a survey," $A C M$ SIGKDD Explorations 2 (1), pp. 1-15.

Krebs, V. E. (2001) "Mapping networks of terrorist cells," Connections (24) 3 , pp. 43-52.

Lawton, G. (2006) "Making business intelligence more useful," IEEE Computer 39 (9), pp. 14-16.

Lewis, J. R. (1995) "IBM Computer Usability Satisfaction Questionnaires: Psychometric Evaluation and Instructions for Use," Internatioal Jourmal of Human-Computer Interaction 7 (1), pp. 57-78.

Loiacono, E. (2002) WebQual ${ }^{\mathrm{TM}}$ : A Web Site Quality Instrument. Proceedings of International Conference on Information Systems (ICIS) Doctoral Consortium, Charlotte, NC, USA, 2002.

Marshall, B., D. McDonald, H. Chen, and W. Chung (2004) "EBizPort: collecting and analyzing business intelligence information," Journal of the American Society for Information and Science and Technology 55 (10), pp. 873891.

Marsico, M. D. and S. Levialdi (2004) "Evaluating web sites: exploiting user's expectations," International Journal of Human-Computer Studies 60 (3), pp. 381-416.

Miller, J. P. (ed.) (2000) Millennium Intelligence: Understanding and Conducting Competitive Intelligence in the Digital Age, Medford, NJ: CyberAge Books.

Mitchell, R. K., B. R. Agle, and D. J. Wood (1997) "Toward a Theory of Stakeholder Identification and
Salience: Defining the Principle of Who and What Really Counts," Academy of Management Review 22 (4), pp. 853-886.

Morse, E. and M. Lewis (2000) "Evaluating visualizations: using a taxonomic guide," International Journal of Human-Computer Studies 53 (5), pp. 637-662.

Myers, J. and A. Well (1995) Research Design and Statistical Analysis. Hillsdale, NJ, USA: Lawrence Erlbaum Associates, Publishers.

Negash, S. (2004) "Business intelligence," Communications of the Association for Information Systems 13, pp. 177195.

Nielsen, J. (1990) "The art of navigating through hypertext," Communications of the ACM 33 (3), pp. 296-310.

Nolan, J. (1999) Confidential: Uncover Your Competitor's Secrets Legally and Quickly and Protect Your Own. New York: Harper Business.

Pazzani, M. (1999) "A framework for collaborative, content-based and demographic filtering," Artificial Intelligence Review 13 (5), pp. 393408.

Penslar, R. L. (2001) Institutional Review Board Guidebook. http://ohrp.osophs.dhhs.gov/irb/irb g uidebook.htm: Office for Human Research Protection, U.S. Department of Health and Human Services.

Pfitzner, D., V. Hobbs, and D. Powers. (2003) A unified taxonomic framework for information visualization. Proceedings of the ACM Asia-Pacific Symposium on Information visualisation, Adelaide, Australia, 2003, pp. 57-66 142.

Pipino, L. L., Y. W. Lee, and R. Y. Wang (2002) "Data quality assessment," Communications of the ACM 45 (4), pp. 211-218.

Rasmussen, N., P. S. Goldy, and P. O. Solli (2002) Financial Business Intelligence: Trends, Technology, Software Selection, and 
Implementation. New York: John Wiley \& Sons, Inc.

Reid, E. O. F. (2003) Identifying a Company's Non-Customer Online Communities: a Proto-typology. Proceedings of the 36th Hawaii International Conference on System Sciences (HICSS-36), Island of Hawaii, HI, USA, 2003.

Robb, D. (2007) Business Intelligence \& Search: A Marriage of Convenience, in ComputerWorld.

Schatz, B. (2002) "The Interspace: concept navigation across distributed communities," IEEE Computer 35 (1), pp. 54-62.

SCIP (2007) "Cl Today," Society of Competitive Intelligence Professionals, http://www.scip.org/pdf/citoday.pdf).

Shneiderman, B. (1996) The eyes have it: a task by data type taxonomy for information visualizations. Proceedings of Visual Languages, Boulder, CO, USA, 1996, pp. 336343.

Smith, A. (1759) The Theory of Moral Sentiments, 1976 Edition by E.G. West edition. Indianapolis: Liberty Fund Inc.

Sorkin, A. R. and M. J. d. I. Merced (2007) Oracle Acquires Hyperion Solutions, in The New York Times. New York, NY.

Srivastava, J. and R. Cooley (2003) "Web business intelligence: mining the Web for actionable knowledge," Journal of Computing 15 (2), pp. 191-207.
Turban, E., J. E. Aronson, and T.-P. Liang (2005) Decision Support Systems and Intelligent Systems, 7th ed. Upper Saddle River, NJ: Prentice Hall.

Wang, R. Y. and D. M. Strong (1996) "Beyond accuracy: what data quality means to data consumers," Journal of Management Information Systems 12 (4), pp. 5-34.

Whitehorn, M. and M. Whitehorn (1999) Business Intelligence: The IBM Solution - Data Warehousing and OLAP. London: Springer-Verlag.

$\mathrm{Xu}$, J. and H. Chen (2005) "CrimeNet Explorer: A framework for criminal network knowledge discovery," ACM Transactions on Information Systems 23 (2), pp. 201-226.

Young, F. W. (1987) Multidimensional Scaling: History, Theory, and Applications. Hillsdale, NJ, USA: Lawrence Erlbaum Associates, Publishers.

Zamir, O. and O. Etzioni. (1999) Grouper: A dynamic clustering interface to Web search results. Proceedings of the 8th World Wide Web Conference, Toronto, Canada, 1999.

Zhong, N., J. Liu, and Y. Yao (eds.) (2003) Web Intelligence: Springer.

Zhou, M. X. and S. K. Feiner. (1998) Visual task characterization for automated visual discourse synthesis. Proceedings of the ACM Conference on Computer-Human Interaction, Los Angeles, CA, 1998, pp. 392-399. 


\section{About the Author}

Dr. Wingyan Chung is an assistant professor in the Department of Operations and Management Information Systems in the Leavey School of Business at Santa Clara University (SCU). He received his Ph.D. in Management Information Systems from The University of Arizona and a MS and BBA from The Chinese University of Hong Kong. His research interests include knowledge management, Web analysis and mining, data and text mining, information visualization, and human-computer interaction. He has over forty refereed publications in Journal of Management Information Systems, Communications of the ACM, IEEE Computer,
International Journal of Human-Computer Studies, Decision Support Systems, and Journal of the American Society for Information Science and Technology, among others. His paper titled "Web searching in a multilingual world" was the cover story of Communications of the ACM, a top-ranked IS journal and the most-frequently-cited journal in computing theory, software, and hardware. Dr. Chung is a principal investigator of the NSF-funded project titled "Living in the KnowlEdge Society (LIKES) (http://www.livingknowledgesociety.org/)," which aims to transform education in computing-related disciplines. He can be reached at wchung@scu.edu. 